\title{
Determinants of Economies of Scale in Large Businesses-A Survey on UE Listed Firms
}

\section{Massimiliano Celli}

Faculty of Economics, Department of Management and Law, Roma TRE University, Rome, Italy.

Email: massimilianocelli@gmail.com

Received May $14^{\text {th }}, 2013$; revised June $14^{\text {th }}, 2013$; accepted June $24^{\text {th }}, 2013$

Copyright (C) 2013 Massimiliano Celli. This is an open access article distributed under the Creative Commons Attribution License, which permits unrestricted use, distribution, and reproduction in any medium, provided the original work is properly cited.

\begin{abstract}
This article aims at giving a contribution to the issue of the determinants of economies of scale in large businesses. After the economies of scale definition, the study identifies and analyzes the economies of cost that, according to most of the well-established literature, contribute jointly to originate the phenomenon at stake. Then, the study analyzes the information collected through specially created questionnaires from a sample of businesses listed on regulated European markets. The aim of the questionnaires is to verify if such companies obtain economies of scale in their productive processes and, if so, to identify which of the cost economies previously analyzed are actually achieved. Finally, the article analyzes data and information obtained through the questionnaires and draws some conclusions. Specifically, the study tries to overcome a one-way and sole interpretation of the economies of scale phenomenon in favour of distinction in economies of scale of II level ("in the strict sense") and economies of scale of I level ("generic").
\end{abstract}

Keywords: Economies of Scale; Big Enterprises; Competitiveness

\section{Introduction}

The size and structure of businesses change over time as they try to constantly adjust to the size, nature and characteristics of the markets they interact with. In order to compensate for the "natural selection" processes that inevitably lead to the elimination of marginal individuals, that is of those units which are unable to produce a given amount of output at minimal absolute costs, and in order to survive in the long term, a firm needs to organize its operational processes in terms of both technical and economic efficiency, that is, it has to maximize the output of factors in the production cycle. In fact, the growth in size obtained either by its own force or by merging with other firms, is often motivated by the search for scale economies. Such economies are by nature a "dynamic" phenomenon resulting from a process of growth in the firm size that continues in time. Consequently, economies of scale need to be planned over a long-term time horizon (that is a sequence of short periods of time close to each other and characterized by a given level of productivity and fixed overheads) [1].

Scale economies consist of potential reductions of average costs associated with higher levels of productivity, which is measured by the quantity of output that can be produced in the time unit [2]. Or, they may also describe the economic advantages that show when higher volumes of output are produced with respect to smaller ones and that result in cost reduction per unit for that particular output, and for the same price of inputs [3].

Economies of scale are expressed by the following: $2 c(q)>c(2 q)$, where $c(q)$ is the cost per unit of output and $\mathrm{c}(2 \mathrm{q})$ the cost of double the output. Broadly speaking, economies of scale occur when all other things being equal, increasing outputs lead to a less than proportional increase in overall costs (that is, output costs per unit decrease). Or, when increasing production costs in constant proportion result in a more than proportional output [4].

In Section 2 of this article, we identify and analyze the economies of cost that, according to most of the wellestablished literature, contribute jointly to originate scale economies. In Section 3, we analyze the information collected through specially created questionnaires from a sample of businesses listed on regulated European markets. The aim of the questionnaires is to verify if such companies obtain economies of scale in their productive processes and, if so, to identify which of the cost economies analyzed in Section 2 of this article are actually achieved. In Section 4, we analyze data and information 
obtained through the questionnaires and draw some conclusions.

\section{Origins of Economies of Scale}

\section{a) Full capacity economies [5-7]}

The origins of full capacity economies (also called economies of expansion) $[8,9]$ are to be found in the higher or lower levels of indivisibility of factors of production, which cannot be acquired on the supplying markets in infinitely divisible fractions, either bigger or smaller $[10,11]$. Businesses are very seldom able to tailor their productive capacity to the precise and actual level of market demand.

In other words, if a given physical capital is available to produce a given output requested by the market, it is likely that businesses will not be able to supply the factors of production having the exact productive capacity asked for. More realistically, the physical capital "available" will be smaller (resulting in the under sizing of production capacity) or greater (resulting in the over sizing of production capacity) than the specific market demand. In the first case, saturation of installed physical capital will occur (and consequently product cost per unit is minimized, with fixed costs of the structure distributed over the highest quantity of output possible), as well as impossibility to meet the overall market demand. In the second case, under-utilization of the existing production capacity will take place and product costs per unit will go up accordingly, since fixed costs of the structure are distributed on a lesser output than the maximum technical level possible.

Moreover, full capacity economies correspond to the efficiency improvements that businesses obtain when, given a certain physical capital in a given period of time (a short period interval), its use is increased until the maximum technical level possible is approached, so that fixed costs of the structure are distributed on a higher quantity of final goods (with consequent reduction of product cost per unit).

b) Economies that recycle by-products and manufacturing waste $[12,13]$

In addition to primary products, that is the target goods of the business activity, industrial businesses produce by-products and/or waste during most of the manufacturing processes. They are "lost" in economic and commercial terms during the process itself (as it happens for the so called heavy oil residue, obtained from the cracking of petroleum products).

The reason for that loss is economic rather than technological (such as the use of scarcely efficient production plants), since recycling such residues, in order to reuse them in the productive process, or to sell them separately, normally involves relatively high expenses to modify their technical and economic characteristics and make them suitable for recycling. In other words, it is not so much a matter of developing procedures to recycle production waste, which is technically a relatively easy process, but of making such "changes" economically convenient or at least affordable for the business.

When its productive capacity expands, a business is able to cover the costs it incurs to recycle and reuse byproducts (since costs can be distributed on a greater number of end products) as well as to save the money necessary for their disposal on the one hand, and on the other hand to benefit from any income derived from selling them.

c) Economies of massed reserves [14-16]

Any businesses and industrial businesses in particular have to create and keep a certain amount of stock over time, both the traditional type, such as spare parts, end products etc. and pecuniary reserves to ensure ordinary productive activity and reduce the risk of slowing down or stopping the activity itself due to the stock out of such factors of production.

In order to build and keep such reserves businesses incur in relatively high expenses which are determined not only by the relevant acquisition costs but also by the opportunity cost, that is the profit that the business could have made if the money invested to purchase such reserves had been used for more profitable investments. Since cost of reserves indirectly affects the product cost per unit, it is clear that handling stocks in such a way as to minimize their size is a fundamental source of competitive advantage.

Since volumes of production and, consequently, the business size increases in a less than proportional way, costs associated with stocking and maintenance of inputs not immediately used in the productive activity increase by a less than proportional way. A larger business is able in fact to use such reserves in a more economical way (the so called increasing stochastic outputs) by improving the distribution of the above mentioned technical risks and therefore by reducing of the incidence of costs associated to such risks-over a higher number of productive operations. Since the aim of reserves is to "insure" the business against statistically probable events likely to undermine proper production activity, the amount of such reserves depends partly on the management ability to produce forecast plans, but also on the occurrence of a set of accidental events (machines break down, strikes etc.) that can be forecast only with great approximation. Under this perspective, the business management based on large productive size is able to activate, according to the law of large numbers, a great deal of statistically independent events whose opposing variations balance each other out and realize a form of "self insurance".

For example, let us consider two hospitals of the same size that have to keep adequate reserves of blood by law 
(which is sent to the incinerator after a month of storage). Even if each hospital expects to use twenty litres of blood a month, it will in fact stock fifty liters to reduce the stock out risk. If one of the two hospitals should run out of blood, it is highly unlikely that the other hospital will find itself in the same situation at the same time. If the two hospitals joined their reserves of blood they could:

- Keep the same reserve levels (a hundred liters overall) with a risk of stock-out lower that the two hospitals considered separately, or

- Cut the reserves down to, say, eighty litres. The hospital deriving from the "merger" would have lower storage cost than the two hospitals considered separately, with yet the same stock out risk $[17,18]$.

d) Economies of product multiple [19-22]

Any industrial productive process consists of an endless series of physical and chemical transformations, in which the input (except for the first one) is partly or entirely determined by the output of the previous phase.

When in a productive process factors of different nature characterized by dishomogeneous operating potentials work together (plants, machines, labour, etc.), it is necessary to balance the productive capacities of each factor with the rhythm determined by the characteristics of the process. To obtain such balance, the level of cooperation among the various factors of production needs to be increased, as well as the total output. Small scale production is therefore inefficient when the optimal proportion in the use of factors of production is not achieved. According to the hypothesis of perfect divisibility such optimum proportion might be obtained by dividing each aggregate in infinitively divisible units; however, such division results in the non-existence of cost economies as the business size grows, and we may assume that such economies are explained by the above mentioned imperfect indivisibility [23].

In other words, if the firm works in sequences (goods undergo a series of modifications following a sequence before the final product is obtained), the series of transformations are generally achieved through factors that are dishomogeneous in type and degree of performance. Consequently, given the assumption that the balance of a production sequence is perfect when all factors employed are completely saturated, that is used to their maximum productive capacity, equilibrium will have to be attained through a flow of ouput equal to the lowest common multiple of the productive capacity of each single factor. With a volume of production inferior to the lowest common multiple, the most productive factors would be underused in part, whereas the less efficient ones would turn into bottlenecks for the production chain.

e) Economies of large machines [24-27]

Given the sequence of physical and technical opera- tions that characterize productive processes, it is evident that, for each operation, the factors of production used are characterized by specific sizes, surfaces and volumes. Whereas the choice of shape and material of the factors of production is influenced by cost and technological factors, the choice of their size is determined by cost factors exclusively.

The benefits in terms of costs that a business can obtain by using plants and machines of "big" size in its productive processes derive mainly from:

- Lower acquisition costs and/or manufacturing costs compared to smaller factors (the so called "squarecube” law). Broadly speaking, costs associated with manufacturing of factors of production of larger size are inferior in proportion to smaller-sized factors, using the same technology (for example, the quantity of work and materials needed to make a $50 \mathrm{HP}$ engine are roughly the same required for a $100 \mathrm{HP}$ engine) [28]. Ad adiuvandum, in the case of specific types of plants and machines (such as tanks, ships, boilers etc.), manufacturing cost increases according to a quadratic law, whereas the relative productive capacity increases by a cubic law. In fact, manufacturing costs tend to grow in proportion to the surface, whereas productive capacity increases with the volume [29]. In the case of oil pipelines, for example, the cost of oil transport is directly proportional to the friction between the liquid and the pipe where it flows. Since the friction increases with larger surface, the costs of transportation increase with the surface of the oil pipeline, whereas the quantity of oil that can be pumped into the plant depends on the volume of the pipeline. Therefore, the average cost of the pipeline decreases when the fuel delivery is higher [30];

- Lower costs of using the factor and operating costs with respect to capital factors of minor size. Resource savings include not only lower manufacturing costs (as mentioned above) but also the expenses directly connected with the use of the same factors: in fact, cost for direct and indirect labour, electricity and maintenance increase in a less than proportional way when the productive size increases (or they remain unchanged) [31];

- Higher technical and economical output. Higher productivity is obtained not only from state of the art machinery and plants but also from factors with larger size, since the loss of efficiency due to friction loss, material waste, heat dispersion etc. is lower [32].

f) Economies of technological and managerial changes [33-37]

By increasing the business size, it is possible to change the technical features of the productive process and also to renovate the overall management organization, due to greater division and specialization of work, fragmenta- 
tion and standardization of job tasks and to the level of mechanization of production (which is more "capital intensive"). In other words, the implementation of Smiths' principle of division of labor $[38,39]$ transforms complex processes into a sequence of simple operations performed with the help of highly specialized factors of production (workforce and capitals). Confined to a limited number of tasks, each worker develops automatisms and routines, acquires "conditioned habits" which lead to high speed levels and greater skill on their particular subtask.

Production cost reduction associated with the transition from small scale artisanal production (that is with higher variable costs) to mass production is possible only if the firm attains a specific size. Smith's production methods would prove uneconomical if the volume of output were not sufficient to compensate for the high capital lock-ins that such methods involve. Consequently, only large businesses can support such elevated costs (also because they are distributed on higher production volumes) at first, and then enjoy the considerable benefits derived from the minor incidence on the product unit of running costs.

g) Pecuniary economies [40-43]

These cost economies can be obtained by businesses that thanks to their size are in a stronger position on the markets of factors of production compared to small and medium sized enterprises. In fact they enjoy better trading conditions and can purchase goods and services necessary to the productive cycle at more convenient prices. They also have more opportunities and better conditions to access the capital market (in terms of costs and guarantees they can offer).

As for supply economies, it is widely known that, compared to small and medium sized enterprises, great buyers are able to control the markets and impose lower prices for the acquisition of goods and services. They also enjoy better contractual terms. The advantages associated with large productive size are the following: 1) real savings on orders and on shipping costs, due to the greater quantity purchased (the so called "quantity discounts"); 2) overall more favorable supply contract and better contractual terms, such as improved quality of the supplied goods or goods that reflect the needs of the business more suitably.

As for the economies of capital collection, they derive from the centralized management of important financial flows made possible by the large entrepreneurial size and which results in easier access to credit, in lower credit costs and greater profits compared to small and medium-sized enterprises [44]. Such economies can be explained not only by the cost of the borrowed capital (that is the interest rate) but also by the burdens connected to negotiations and to the issuing of financial instruments (such as bonds in particular). Such burdens are in fact independent from the financial value of the operation.
Moreover, the burdens decrease as the volumes themselves increase, beyond certain limits. In the case of payment of the borrowed capital, it is proportional to the level of the risk involved in the financing operation. In this respect the interest rates applied by banks to loans given to large businesses are often inferior (very often against higher amount granted) to those applied for the small and medium-sized enterprises. Such facilitations are motivated by the higher financial strength of a large firm, the credibility and the trust of the banks it enjoys and, last but not least, the minor rate of bankruptcy compared to the averages in the sector.

h) Economies of experience/learning [45-48]

The phenomenon of "experience" factor was firstly quantified in 1936, when the commander of an air force base observed that the number of hours needed to put an airplane together decreased regularly by $10 \% / 15 \%$ every time aircraft production doubled (the Boston Consulting group fixed such at $10 \%-25 \%$ for various industrial sectors in the 1970s) [49]. In the light of such evidence and since the phenomenon did not concern labour only but also all the various factors of production, the existence of a Law of experience was posited. According to this law the cost per unit of a given product decreases by a fixed percentage each time the total cumulative production doubles. The cumulative product rather than the product relevant to a given period of time is taken into account in order to differentiate quantitatively the cost advantages deriving from the learning effect and those deriving from other effects of scale [50,51].

Assuming that the economies of learning concern both cost advantages and improvement in the quality and quantity of the overall productive process, deriving from growing experiences and technical skills at all levels of the firm organization chart, the determinants of such economies can be described as follows:

- Better training and organization as well as specialization of the human component in the productive process (involving all levels of the organigram, as said before);

- The labour factor develops automated habits and skills by the "sedimentation" of previous experiences;

- Manual and mechanic work are better balanced and the factors of production are more efficiently synchronized through optimization of the plant lay-out and of sequences of production, since production times and relevant know-how are developed more precisely.

\section{Data Collection}

\subsection{Methodology}

An appropriate questionnaire has been sent to 140 businesses (to the investor relations and/or administrative offices) quoted on regulated European markets. The sam- 
ple consists of:

- 25 companies listed on the London Stock Exchange;

- 25 companies listed on the Euronext Paris;

- 25 companies listed on the Frankfurter Wertpapierborse (Germany);

- 25 companies listed on the Borsa di Milano (Italy);

- 20 companies listed on the Bolsa de Madrid (Spain);

- 20 companies listed on the Beurs van Berlage (The Netherlands).

Companies have been selected from each of the mentioned regulated markets on the basis of their highest values of capitalization and on the fact that in the period 2001-2011 their income had increased of at list 50\%. Insurance companies, financial companies and credit institution have not been included in the sample.

The questions in the questionnaire (which is not included) aim to verify if, according to the management of each company:

1) The company realizes productive economies that can be defined 'of scale' in their productive processes;

2) Which of the following cost economies businesses realize in actual fact (these economies have been analyzed in detail in Section 2 of the present article):

a) Full capacity economies;

b) Economies that recycle by-products and manufacturing waste;

c) Economies of massed reserves;

d) Economies of product multiple;

e) Economies of large machines;

f) Economies of technological and managerial changes;

g) Pecuniary economies;

h) Economies of experience/learning.

\subsection{Data Collection}

Out of the 140 questionnaires we sent, 23 were returned to us. The data that emerge are the following:

1) As for question one, 23 companies (that is all of the companies in the sample) declare that they realize productive economies that can be defined as "economies of scale" in their productive process;

2) As for question two:

a) N. 21 state that they realize full capacity economies;

b) N. 6 state that they realize economies that recycle by-products and manufacturing waste;

c) N. 9 state that they realize economies of massed reserves;

d) N. 17 state that they realize economies of product multiple;

e) N. 23 state that they realize economies of large machines;

f) N. 11 state that they realize economies of technological and managerial changes;

g) N. 23 state that they realize pecuniary economies; h) N. 14 state that they realize economies of experience/learning.

\section{Data Analysis and Conclusions}

In the light of the information collected from the questionnaires, we believe that the variety of cost economies that businesses can realize by increasing production should not be included in one single category of economies of scale without any differentiation.

There is no two-way process between the large size of a business (or the fact that it has increased its size) and its capacity to realize all those economies that according to the traditional theory are altogether considered as economies of scale, given that:

- If a business is able to obtain the above mentioned economies of cost, then its size is dimensionally "large". Reduced production cost and growth in size are in fact strictly connected since such long term quantitative economies cannot exist without a large productive size;

- Conversely, being a dimensionally "large" business, or having increased its size is not sufficient in itself to guarantee the achievement of the above mentioned economies of cost.

We are therefore convinced that a one-way and sole interpretation of the economies of scale phenomenon should be abandoned in favour of distinction in economies of scale of II level ("in the strict sense") and economies of scale of I level ("generic").

Economies of scale of II level concern the reduction per unit cost of production determined by:

b) Economies that recycle by-products and manufacturing waste;

c) Economies of massed reserves;

f) Economies of technological and managerial changes;

h) Economies of experience/learning.

Economies of scale of I level are originated by:

a) Full capacity economies;

d) Economies of product multiple;

e) Economies of large machines;

g) Pecuniary economies.

"Generic" economies of scale can be obtained through the mere growth in size (independently from the relevant ways of implementation) whereas the growth in size is a necessary but not sufficient condition to obtain economies of cost that originate economies of scale "in the strict sense".

Such assumption is based on the data contained in the questionnaires. As a matter of fact the 23 companies analyzed are "large" in size (or have increased their size within the period 2001-2011 in any case) and a high percentage of them (91\%) have realized economies of cost associated with economies of scale of I level. Conversely, 
few companies (43\%) have realized economies of cost that originate economies of scale of II level, confirming that the latter represent the most qualifying advantages, though more uncertain to obtain, associated with the growth in size of a company.

In conclusion:

- If a business is able to enjoy benefits in cost savings determined by the presence of economies of scale of II level, than it is also "large" in size. There is in fact a two-way correspondence between cost reductions and the physical size of a business, as such quantitative economies cannot exist in the long term without the necessary space characterized by large size;

- On the other hand, the fact that a business is presumptively "large" or that has undergone a process of expansion, is not sufficient in itself to guarantee the existence of the above mentioned economies of scale of II level.

\section{REFERENCES}

[1] G. J. Stigler, “The Economies of Scale,” Journal of Law and Economics, Vol. 1, No. 1, 1958, pp. 54-71. doi:10.1086/466541

[2] C. F. Pratten and R. M. Dean, "The Economics of Large Scale Production in British Industry, an Introductory Study," Cambridge University Press, London, 1965, p. 12.

[3] M. Bellandi, "Economie di Scala e Organizzazione Industriale,” Il Mulino, Bologna, 2007, p. 29.

[4] A. Zattoni, "Economia e Governo Dei Gruppi Aziendali," Egea, Milano, 2008, p. 80.

[5] F. M. Scherer, "Economies of Scale and Industrial Concentration,” International Institute of Management, Beriln, 1975, p. 23.

[6] T. Dunne, M. Roberts and L. Samuelson, "Patterns of Firm Entry and Exit in US Manufactoring Industries," Rand Journal of Economics, Vol. 19, No. 4, 1988, pp. 495-515. doi:10.2307/2555454

[7] G. Hamel and C. K. Prahalad, "Strategic Intent,” HBR Press Book, Boston, 2010, pp. 28-43.

[8] E. T. Penrose, "The Theory of the Growth of the Firm," Wiley, New York, 1959, p. 43.

[9] D. Besanko, D. Dranove and M. Shanley, "Economics of Strategy,” Wiley, New York, 2009, p. 90.

[10] H. H. Liebhafsky, “The Nature of Price Theory,” Dursey Press, Cambridge, 1968, p. 241.

[11] A. D. Chandler, "Scale and Scope: The Dynamics of Industrial Capitalism,” Belknap, Cambridge, 1994, p. 411.

[12] J. Muller, “La Dimensione Dell'impresa e L'integrazione Verticale,” Economia Politica e Industriale, No. 1, 2003, pp. 9-21.

[13] C. F. Pratten, "A Survey of the Economies of Scale," Columbia University, New York, 1988, p. 27.

[14] R. S. Edwards and H. Townsend, "Business Enterprise:
Its Growth and Organization,” Macmillan, Londra, 1961, p. 183.

[15] J. Haldi and D. Whitcomb, "Economies of Scale in Industrial Plants," Journal of Political Economy, Vol. 75, No. 4, 1967, pp. 373-385. doi:10.1086/259293

[16] L. J. Truett and D. B. Truett, "A Cost-Based Analysis of Scale Economies in the French Auto Industry," International Review of Economics and Finance, Vol. 16, No. 3, 2007, pp. 369-382. doi:10.1016/j.iref.2005.08.001

[17] W. Lynk, “The Creation of Economic Efficiency in Hospital Mergers,” Journal of Health Economics, Vol. 14, No. 5, 1995, pp. 507-530. doi:10.1016/0167-6296(95)00019-4

[18] M. Weaver and A. Deolalikar, "Economies of Scale and Scope in Vietnamese Hospitals," Social Science and Medicine, Vol. 59, No. 1, 2004, pp. 199-208. doi:10.1016/j.socscimed.2003.10.014

[19] J. V. Robinson, "The Economics of Imperfect Competition,” Macmillan, London, 1969, p. 346.

[20] C. F. Pratten, "Economies of Scale in Manufactoring Industries,” Cambridge University Press, Cambridge, 1971, p. 6.

[21] A. Cockerill, "Economies of Scale and the Structure of the Steel Industry,” The Business Economist, Vol. 6, No. 1, 1974, pp. 19-36.

[22] K. De Witte and C. M. Rui, "Big and Beautiful? On NonParametrically Measuring Scale Economies in Non-Convex Technologies,” Journal of Productivity Analysis, Vol. 35, No. 3, 2011, pp. 213-226. doi:10.1007/s11123-010-0191-1

[23] E. H. Chamberlin, "Towards a More General Theory of Value,” Oxford University Press, Oxford, 1957, p. 182.

[24] E. A. G. Robinson, "The Structure of Competitive Industry,” Cambridge University Press, Cambridge, 1997, p. 28.

[25] R. C. Marques and K. De Witte, "Is Big Better? On Scale and Scope Economies in the Portuguese Water Sector," Economic Modelling, Vol. 28, No. 3, 2011, pp. 10091016. doi:10.1016/j.econmod.2010.11.014

[26] P. Crompton and J. P. Lesourd, "Economies of Scale in Global Iron-Making,” Resources Policy, Vol. 33, No. 2, 2008, pp. 74-82. doi:10.1016/j.resourpol.2007.10.005

[27] R. I. Anderson, R. Fok, T. Springer and J. Webb, “Technical Efficiency and Economies of Scale,” European Journal of Operational Research, Vol. 139, No. 3, 2002, pp. 598-612. doi:10.1016/S0377-2217(01)00183-7

[28] L. Bruni, "Economie Interne di Scala a Tecnica Immutata,” L'Industria, No. 3, 1964, pp. 116-132.

[29] F. T. Moore, "Economies of Scale, Some Statistical Evidence,” The Quarterly Journal of Economics, Vol. 73, No. 2, 1959, pp. 232-245. doi:10.2307/1883722

[30] L. Cockenboo, "Production Functions and Cost Functions,” In: E. Mansfield, Ed., Managerial Economics and Operations Research, Norton, New York, 1999, p. 110.

[31] F. Momigliano, "Le Economie di Scala,” In: P. Saraceno, Ed., Letture di Gestione Della Produzione, Franco Angeli, Milano, 2004, p. 93.

[32] M. Canesi, “Attualità Delle Economie di Scala: Una Verifica Empirica su un Comparto Della Meccanica Strumen- 
tale,” Economia e Politica Industriale, No. 2, 1991, pp. 103-133.

[33] B. Gold, "Changing Perspectives on Size, Scale and Return. An Interpretative Survey," Journal of Economic Literature, Vol. 19, No. 1, 1981, pp. 5-33.

[34] W. Baldamus, "Mechanization, Utilization and Size of Plant," The Economic Journal, Vol. 63, No. 249, 1953, pp. 50-69. doi:10.2307/2226750

[35] M. J. Piore and C. F. Sabel, "The Second Industrial Divide,” Basic Books, Londra, 1984, p. 95.

[36] H. Chaug-Ing and L. Hui-Chieh, “An Integrated Plant Capacity and Production Planning Model for High-Tech Manufacturing Firms with Economies of Scale,” Interna- tional Journal of Production Economics, Vol. 118, No. 2, 2009, pp. 486-500.

[37] E. G. Tsionas and J. Loizides, “A Note on Joint Estimation of Scale Economies and Productivity Growth Parameters," International Journal of Production Economics, Vol. 70, No. 1, 2001, pp. 37-43. doi:10.1016/S0925-5273(00)00041-4

[38] A. Smith, "Wealth of Nations," Prometheus Books, New York, 1991.

[39] E. A. Young, "Increasing Returns and Economic Progress,” The Economic Journal, Vol. 38, No. 152, 1928, pp. 527-542. doi:10.2307/2224097

[40] C. F. Pratten, "The Competitiveness of Small Firms," Cambridge University Press, London, 1991.

[41] A. Silberston, "Economies of Scale in Theory and Practice,” The Economic Journal, Vol. 82, No. 325, 1972, pp. 369-391. doi:10.2307/2229943

[42] J. Mingzhou, D. S. Wu and E. Murat, "Multiple Unit Auctions with Economies and Diseconomies of Scale,"
European Journal of Operational Research, Vol. 174, No. 2, 2006, pp. 816-834.

[43] C. Guy, D. Bennison and R. Clarke, "Scale Economies and Superstore Retailing: New Evidence from UK," Journal of Retailing and Consumer Services, Vol. 12, No. 3, 2005, pp. 73-81. doi:10.1016/j.jretconser.2004.03.002

[44] S. J. Prais, “The Evolution of Giant Firms in Britain: A Study of the Growth of Concentration in Manufactoring Industries,” University Press, Cambridge, 1976.

[45] J. P. Sallenave, "The Use and Abuse of Experience Curves,” Long Range Planning, Vol. 18, No. 1, 1985, pp. 64-72. doi:10.1016/0024-6301(85)90180-3

[46] W. Abernathy and K. Wayne, "The Limits of Experience curves,” Harvard Business Review, Vol. 52, No. 9, 1974, pp. 109-119.

[47] D. Jardot, W. Eichhammer and T. Fleiter, "Effects of Economies of Scale and Experience on the Cost of Energy Efficient Technologies,” Energy Efficiency, Vol. 3, No. 4, 2010, pp. 331-346. doi:10.1007/s12053-009-9074-6

[48] R. D. Foreman and E. Beauvais, "Scale Economies in Cellular Telephony: Size Matters,” Journal of Regulatory Economics, Vol. 16, No. 3, 1999, pp. 297-306. doi:10.1023/A:1008131223498

[49] C. L. Benkard, "Learning and Forgetting: The Dynamics of Aircraft Production,” Yale University, New Haven, 1998.

[50] M. Liebermann, "The Learning Curve and Pricing in the Chemical Processing Industries," Rand Journal of Economics, Vol. 15, No. 2, 1984, pp. 213-228.

[51] M. D. Cohen and L. S. Sproull, “Organizational Learning,” Sage, Thousand Oaks, 1996. 